\title{
Mean platelet volume and coronary plaque vulnerability: an optical coherence tomography study in patients with non-ST- elevation acute coronary syndrome
}

\author{
Jun Wang ${ }^{1+}$, Xing $\mathrm{Li}^{1+}$, Jun $\mathrm{Pu}^{2}$, Siyu Jin ${ }^{1}$, Lu Jia ${ }^{1}$, Xiaomei $\mathrm{Li}^{1}$, Fen $\mathrm{Liu}^{1}$ and Yining Yang ${ }^{1 *+}$ (D)
}

\begin{abstract}
Background: The association between mean platelet volume (MPV) and coronary plaque vulnerability in patients with non-ST-elevation ACS (NSTE-ACS) has not been investigated. We performed a retrospective study to evaluate the association between MPV and plaque vulnerability using optical coherence tomography (OCT).

Methods: Consecutive NSTE-ACS patients who underwent pre-intervention OCT examination in our center were included in this study. Features of coronary plaques in the culprit arteries were classified as rupture, nonrupture with thin-cap fibroatheroma (TCFA), and nonrupture and non-TCFA. ROC analyses were used to determine the predictive efficacy of MPV for plaque rupture, and multivariate logistic regression analysis was performed to evaluate the potential independent predictors of plaque vulnerability.

Results: Overall, 94 patients were included in this study. We identified 17 patients with plaque rupture, 10 with nonrupture with TCFA, and 67 with nonrupture and non-TCFA. ROC analyses showed that MPV $\geq 10.5 \mathrm{fL}$ was predictive of plaque rupture in NSTE-ACS patients. Univariate analyses indicated that patients with higher MPV ( $\geq$ $10.5 \mathrm{fL}$ ) had higher body mass index and poorer lipid profiles compared to those with lower MPV. Moreover, those with higher MPV had higher incidences of plaque rupture and thrombosis (both $P<0.05$ ). Results of multivariate analyses showed that diabetes and higher platelet distribution width (PDW) were independent risk factors of TCFA $(P=0.032$ and 0.046 , respectively), while diabetes, higher BMI, higher PDW, and higher MPV were independent determinants of plaque rupture in our cohorts ( $P$ all $<0.05$ ).
\end{abstract}

Conclusions: Higher MPV is independently associated with higher risk of plaque rupture as evidenced by OCT in our cohort of NSTE-ACS patients.

Keywords: Acute coronary syndrome, Thin-cap fibroatheroma, Optical coherence tomography, Mean platelet volume, Plaque rupture

\section{Background}

Acute coronary syndrome (ACS) is a type of acute coronary artery disease $(\mathrm{CAD})$ that is associated with high morbidity and mortality. ACS is characterized by plaque rupture and acute thrombosis formation in the coronary arteries [1]. Conventionally, plaque rupture and secondary formation of thrombi are considered complex patho

\footnotetext{
* Correspondence: yangyn5126@163.com

'Department of Coronary Heart Disease, the First Affiliated Hospital of

Xinjiang Medical University, Urumqi 830011, China

Full list of author information is available at the end of the article
}

physiological events, and classical CAD risk factors, such as diabetes, smoking, and hypertension, may play important roles in ACS development [2-4]. However, some healthy individuals who do not have the above risk factors can develop ACS [3, 4], suggesting that non-conventional CAD risk factors may underlie ACS pathology. Therefore, identification of novel risk factors for the incidence of plaque rupture in ACS patients is of significance for determining risk stratification and CAD prevention.

Platelets are essential constituents of the blood, and platelet morphology and function play vital roles in the

(c) The Author(s). 2019 Open Access This article is distributed under the terms of the Creative Commons Attribution 4.0 International License (http://creativecommons.org/licenses/by/4.0/), which permits unrestricted use, distribution, and 
pathogenesis of many diseases related to coagulation, thrombosis, inflammation, and endothelial dysfunction [5]. Under pathological conditions, activated platelets release smooth muscle cell (SMC) proliferation factors, stimulate SMC migration, enhance expression of lowdensity lipoprotein (LDL) receptors on the surface of fibroblast cell membranes, and activate inflammatory responses via a variety of pro-thrombotic factors, leading to the progression of atherosclerosis [6]. Previous studies suggested that an increase in mean platelet volume (MPV) is an important indicator of platelet activation, which is also closely related to life span, as well as the ultrastructure and functional status of platelets in circulation [7]. Indeed, previous studies mainly focused on the relationship between MPV and CAD risk [8, 9], and confirmed that MPV is a valuable prognostic factor in CAD patients $[10,11]$. However, the association between MPV and the risk of acute coronary events, to the best of our knowledge, is under investigated. Particulalry, the risk prediction for patients with non-ST-elevation ACS (NSTE-ACS), including unstable angina and non-STelevation myocardial infarction, can be challenging. Using optical coherence tomography (OCT), the optimal intraluminal image tool to evaluate characteristics of coronary plaques, we investigated the potential association between MPV and OCT-evidenced coronary plaque vulnerability in NSTE-ACS patients. Results of our study may be helpful for identifying novel risk factors of plaque rupture and improvement of risk stratification of patients with NSTE-ACS.

\section{Methods}

\section{Patients and study design}

Patients with NSTE-ACS who underwent preintervention OCT examination during coronary angiography (CAG) admitted to the First Affiliated Hospital of Xinjiang Medical University from January 2015 to September 2018 were consecutively screened for study

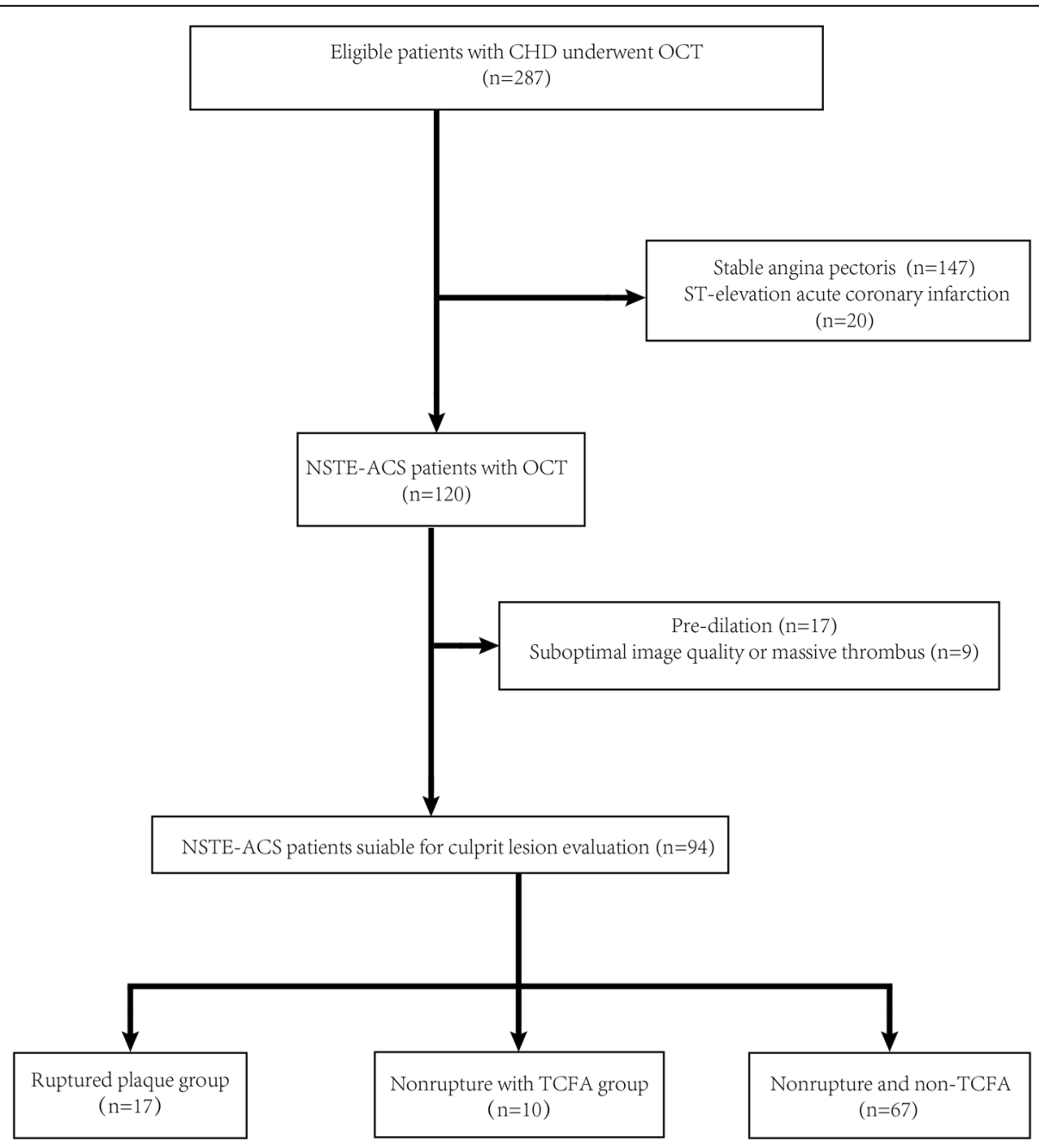

Fig. 1 Flowchart of patient inclusion 
inclusion. NSTE-ACS was diagnosed according to previously established guidelines [12]. The flow chart for patient inclusion and exclusion is shown in Fig. 1. Demographic features, clinical characteristics, CAD risk factors, blood biochemical parameters, echocardiogram (ECG), echocardiography, coronary angiography (CAG), and OCT results were collected. Culprit vessels were determined by CAG, and we focused on plaque vulnerability evidenced by OCT in the culprit vessels. The study protocol was approved by the ethics committee of the First Affiliated Hospital of Xinjiang Medical University before patient enrollment.

\section{Definitions of CAD risk factors}

Hypertension was diagnosed if the patient had a blood pressure $\geq 140 / 90 \mathrm{mmHg}$ on at least three separate occasions or was being actively treated with antihypertensive drugs [13]. Diabetes mellitus was diagnosed if the patient had a fasting plasma glucose $\geq 7.1 \mathrm{mmol} / \mathrm{L}$ or a two-hour post load glucose $\geq 11.1 \mathrm{mmol} / \mathrm{L}$ [14], and in those with a definite history of diabetes and who were being treated with glucose-lowering agents. The diagnostic criteria for hyperlipidemia were based on the Guideline of Chinese Adult Dyslipidemia Prevention and Treatment (2016) [15]. Body mass index (BMI) was calculated by dividing a patient's weight in kilograms by the height in meters squared. Smoking was defined as current smoking habit.

\section{Blood tests}

Blood samples from the included patients were drawn immediately after hospital admission,sent immediately for laboratory analysis. MPV was significantly reduced in response to biphasic antiplatelet agents $[16,17]$. Therefore, blood collection was performed before the application of an anti-platelet aggregation drug. Blood tests were performed using standard methods in the Central
Laboratory of the First Affiliated Hospital of Xinjiang Medical University.

\section{Coronary angiography and OCT analysis}

All patients underwent coronary angiogram within $24 \mathrm{~h}$ of admission. All enrolled patients received CAG via a standard method by experienced cardiologists. Quantitative analysis of coronary artery stenosis was determined by experienced interventionists. A commercially available C7-XR OCT intravascular imaging system (C7-XR TM OCT Intravascular Imaging System, St. Jude Medical, St. Paul, MN, USA) was used for OCT examination. OCT images were analyzed based on established OCT diagnostic criteria. Specifically, plaque rupture was identified by fibrous cap discontinuity with a cavity formed inside the plaque (Fig. 2a) [18, 19]. Thin-cap fibroatheroma (TCFA) was defined as a plaque with a maximal lipid arc $>90^{\circ}$ and the thinnest fibrous cap thickness was $\leq 65 \mu \mathrm{m}$ (Fig. 2b) [18]. Two independent investigators (J.L and S. C.F) who were blinded to clinical angiographic data analyzed the OCT images and the laboratory data using a dedicated off-line review system (St. Jude Medical) at the core laboratory (Xinjiang Medical University). Disagreements were solved by consensus with a third investigator.

\section{Statistical analysis}

All analyses were performed using SPSS 23.0 for Windows statistical software (SPSS Inc., Chicago, IL, USA). Continuous variables are expressed as means and standard deviations, whereas categorical variables are presented as percentages. The Chi-square $\left(\chi^{2}\right)$ test was used for comparing categorical variables. Significant variables in univariate analysis were subsequently included in the multivariate logistic analysis. A $P$ value $<0.05$ was considered statistically significant.
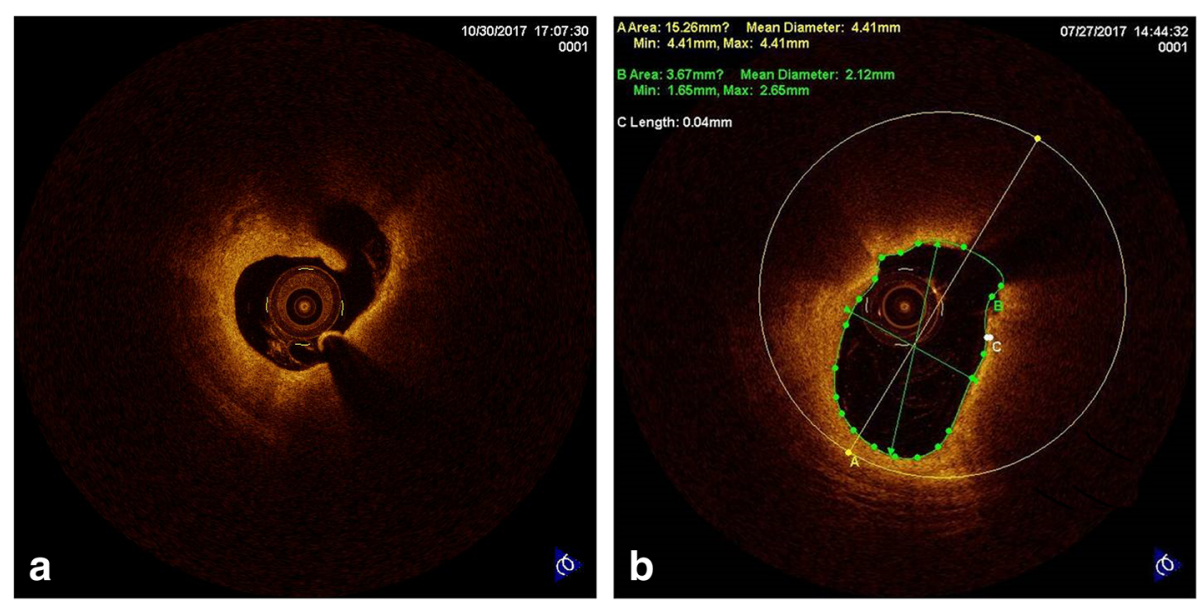

Fig. 2 Representative optical coherence tomography images of plaque rupture and thin-cap fibroatheroma. (a) Plaque rupture, (b) Thin-cap fibroatheroma (TCFA) 


\section{Results}

ROC analyses for the association between MPV and plaque rupture

Overall, 94 patients with NSTE-ACS were included in this study, including 33 with non-ST-segment-elevation acute myocardial infarction, and 61 with unstable angina pectoris. OCT analyses for the culprit lesions indicated that 17 patients had plaque rupture, 10 had nonrupture with TCFA, and 67 had nonrupture and non-TCFA. ROC curve analysis showed that MPV was predictive of plaque rupture shown in Fig. 3, and a cut-off value of $10.5 \mathrm{fL}$ of MPV conferred a sensibility of $88.2 \%$ and a specificity of $62.3 \%$. The area under the ROC was 0.776 , indicating good validity $(P$ $<0.001,95 \%$ confidence interval $(\mathrm{CI}): 0.671-0.880)$.

\section{Patient characteristics according to MPV levels}

Patient characteristics according to MPV levels are presented in Table 1 . Those with higher MPV $(\geq 10.5$ $\mathrm{fL}$ ) had higher BMI and poorer lipid profiles compared to those with lower MPV levels. No other variables were significantly different with regards to MPV levels.
CAG and OCT findings according to MPV levels

CAG and OCT findings of the included NSTE-ACS patients according to the MPV are presented in Table 2. The prevalence of plaque rupture and thrombosis was higher in the patients with higher MPV $(\geq$ $10.5 \mathrm{fL})$ compared to those with lower MPV levels $(P$ $<0.001$ and $P=0.002$, respectively). There was no significant difference in other CAG and OCT findings between those with higher and lower MPV levels.

\section{Coronary risk factors and laboratory data according to plaque vulnerability}

Coronary risk factors and laboratory data based on plaque vulnerability, including plaque rupture, nonrupture with TCFA, and nonrupture and non-TCFA, are shown in Table 3. Gender, prevalence of diabetes, previous $\mathrm{PCI}$, current smoking, $\mathrm{BMI}, \mathrm{MPV}$ and platelet distribution width (PDW) (all $P<0.05)$ were statistically different among the groups. Patients with ruptured plaque, or non-rupture with TCFA are more likely to be male, diabetic, previous PCI, BMI, MPV, $\mathrm{MPV} \geq 10.5 \mathrm{fL}, \mathrm{PDW}$ as compared with those with non-rupture and non-TCFA ( $\mathrm{P}$ all $<0.05)$.

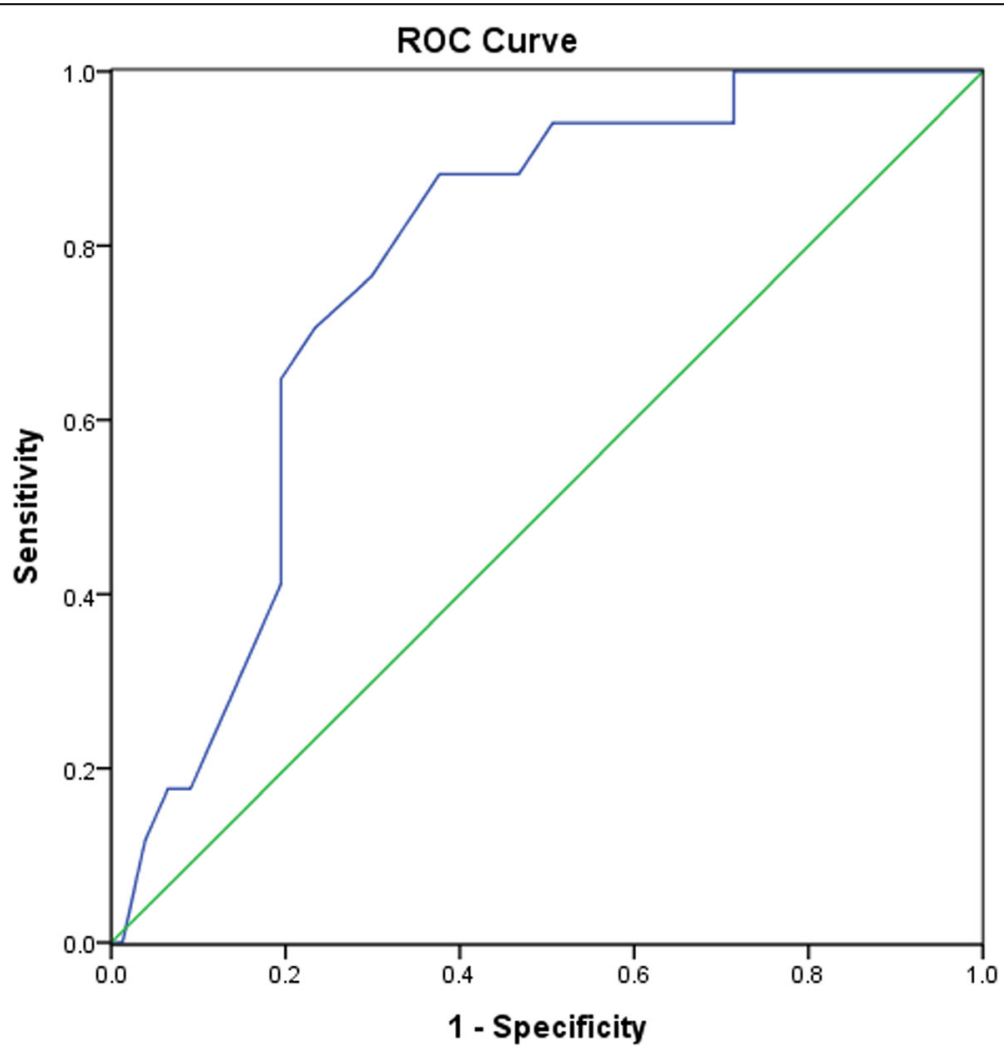

Fig. 3 ROC analyses for the predictive efficacy of MPV for plaque rupture 
Table 1 Patient characteristics according to baseline MPV levels

\begin{tabular}{|c|c|c|c|c|}
\hline & $M P V<10.5 \mathrm{fL}$ & MPV $\geq 10.5 \mathrm{fL})$ & $t / x^{2}$ & $\mathrm{P}$ \\
\hline Male & $33(70.2)$ & $38(80.9)$ & 1.439 & 0.230 \\
\hline Age (year) & $55.04 \pm 13.13$ & $56.60 \pm 9.42$ & 0.659 & 0.512 \\
\hline Hypertension & $19(40.4)$ & $26(55.3)$ & 2.089 & 0.148 \\
\hline Diabetes mellitus & $14(29.8)$ & $23(48.9)$ & 3.610 & 0.057 \\
\hline Smoking & $27(57.4)$ & $30(63.8)$ & 0.401 & 0.527 \\
\hline Drinking & $6(12.8)$ & $12(25.5)$ & 2.474 & 0.116 \\
\hline Family history of CAD & $6(12.8)$ & $10(21.3)$ & 1.205 & 0.272 \\
\hline Previous myocardial infarction & $8(17.0)$ & $7(14.9)$ & 0.079 & 0.778 \\
\hline Previous PCl & $7(14.9)$ & $14(29.8)$ & 3.005 & 0.083 \\
\hline BMI & $24.40 \pm 3.2$ & $25.92 \pm 3.92$ & 2.052 & 0.043 \\
\hline $\mathrm{HDL}-\mathrm{c}(\mathrm{mmol} / \mathrm{l})$ & $1.03 \pm 0.25$ & $0.92 \pm 0.25$ & 2.149 & 0.034 \\
\hline $\mathrm{LDL}-\mathrm{c}(\mathrm{mmol} / \mathrm{l})$ & $2.28 \pm 0.8$ & $2.63 \pm 0.84$ & 2.075 & 0.041 \\
\hline $\mathrm{TC}(\mathrm{mmol} / \mathrm{l})$ & $3.63 \pm 0.92$ & $3.75 \pm 1.1$ & 0.560 & 0.577 \\
\hline $\mathrm{TG}(\mathrm{mmol} / \mathrm{l})$ & $1.81 \pm 0.93$ & $1.8 \pm 0.94$ & 0.069 & 0.946 \\
\hline ApoA1 (g/L) & $1.14 \pm 0.25$ & $1.03 \pm 0.28$ & 2.118 & 0.037 \\
\hline ApoB (g/L) & $0.71 \pm 0.17$ & $0.86 \pm 0.21$ & 3.722 & $<0.001$ \\
\hline Lp(a) (g/L) & $191(100,292)$ & $205(98,363)$ & 0.502 & 0.616 \\
\hline Creatinine $(\mu \mathrm{mol} / \mathrm{L})$ & $76.30 \pm 18.66$ & $80.72 \pm 18.5$ & 1.152 & 0.252 \\
\hline Carbamide (mmol/l) & $5.23 \pm 1.58$ & $5.58 \pm 1.73$ & 1.016 & 0.312 \\
\hline eGFR & $114.17 \pm 36.99$ & $101.1 \pm 35.68$ & 1.744 & 0.085 \\
\hline Uric acid $(\mu \mathrm{mol} / \mathrm{L})$ & $315.93 \pm 103.6$ & $348.14 \pm 83.14$ & 1.663 & 0.100 \\
\hline EF & $60.68 \pm 8.05$ & $59.71 \pm 8.84$ & 0.546 & 0.586 \\
\hline $\mathrm{HbA1c}(\mathrm{mmol} / \mathrm{l})$ & $7.23 \pm 1.34$ & $7.24 \pm 1.4$ & 0.048 & 0.962 \\
\hline Clinical Diagnosis & & & 0.047 & 0.829 \\
\hline UAP & $31(66.0)$ & $30(63.8)$ & & \\
\hline NSTEMI & $16(34.0)$ & $17(36.2)$ & & \\
\hline \multicolumn{5}{|l|}{ Medications } \\
\hline Aspirin & $37(78.7)$ & $32(68.1)$ & 1.362 & 0.243 \\
\hline Statins & $11(23.4)$ & $16(34.0)$ & 1.299 & 0.254 \\
\hline$\beta$-Blockers & $16(34.0)$ & $16(34.0)$ & 0.000 & 1.000 \\
\hline ACEI/ARB & $14(29.8)$ & $22(46.8)$ & 2.881 & 0.090 \\
\hline $\mathrm{CCB}$ & $11(23.4)$ & $11(23.4)$ & 0.000 & 1.000 \\
\hline GRACE risk score & $102.07 \pm 31.11$ & $109.03 \pm 21.24$ & 1.001 & 0.321 \\
\hline
\end{tabular}

$B P C$ blood platelet count, MPV mean platelet volume, $P C T$ thrombocytocrit, $P D W$ platelet distribution width, $R B C$ red blood cell, $P L T$ blood platelet, $H G B$ hemoglobin, $H C T$ hematocrit, $T B i l$ total bilirubin, $D B i l$ direct bilirubin, $C r$ creatinine, $T C$ total cholesterol, $T G$ triglyceride, $H D L-c$ high-density lipoprotein cholesterol, LDL-c low-density lipoprotein-cholesterol, apo-Al Apolipoprotein A1, apo-B Apolipoprotein B, Lp(a), Lipoprotein (a);CCB, calcium channel blockers,

$A C E l$ angiotensin-converting enzyme inhibitors, $A R B$ angiotensin receptor blocker

\section{Independent predictors of plaque vulnerability}

Significant variables in univariate analysis were subsequently included in the multivariate logistic analysis. Multivariate logistic regression analyses showed that diabetes, higher BMI, higher PDW, and higher MPV $(\geq 10.5 \mathrm{fL}$ ) were independent predictors of plaque rupture (P all < 0.05; Model 1; Table 4), while diabetes and higher PDW were independent predictors of TCFA (both $P<$ 0.05; Model 2; Table 4).
CAG and OCT findings according to the vulnerability of the coronary plaques

CAG and OCT findings according to coronary plaque vulnerability, including patients with plaque rupture, nonrupture with TCFA, and nonrupture and non-TCFA, are shown in Table 5. The degree of macrophage accumulation, thrombus, and normal lumen area were significantly different among the three groups $(P=$ $0.005,0.001$, and 0.003 , respectively). No significant 
Table 2 Angiographic characteristics and OCT findings according to MPV levels

\begin{tabular}{|c|c|c|c|c|c|}
\hline & & $M P V<10.5 \mathrm{fL}$ & MPV $\geq 10.5 \mathrm{fL}$ & $t / Z / x^{2}$ & $\mathrm{P}$ \\
\hline $\mathrm{FCT}(\mu \mathrm{m})$ & & $0.11(0.04,0.20)$ & $0.08(0.04,0.12)$ & 1.642 & 0.101 \\
\hline Lipid arc, degree & & $100(0,178)$ & $149(0,229)$ & 1.192 & 0.233 \\
\hline \multirow[t]{2}{*}{ Rupture (\%) } & No & $45(95.7)$ & $32(68.1)$ & 12.136 & $<0.001$ \\
\hline & Yes & $2(4.3)$ & $15(31.9)$ & & \\
\hline \multirow[t]{2}{*}{ Erosion (\%) } & No & $40(85.1)$ & $35(74.5)$ & 1.649 & 0.199 \\
\hline & Yes & $7(14.9)$ & $12(25.5)$ & & \\
\hline \multirow[t]{5}{*}{ Macrophage accumulation } & 0 & $27(57.4)$ & $15(31.9)$ & 7.718 & 0.057 \\
\hline & 1 & $10(21.3)$ & $18(38.3)$ & & \\
\hline & 2 & $10(21.3)$ & $12(25.5)$ & & \\
\hline & 3 & $0(0.0)$ & $1(2.1)$ & & \\
\hline & 4 & $0(0.0)$ & $1(2.1)$ & & \\
\hline \multirow[t]{2}{*}{ Vasa vasorum } & No & $44(93.6)$ & $43(91.5)$ & 0.000 & 1.000 \\
\hline & Yes & $3(6.4)$ & $4(8.5)$ & & \\
\hline \multirow[t]{2}{*}{ Thrombus } & No & $40(85.1)$ & $26(55.3)$ & 9.970 & 0.002 \\
\hline & Yes & $7(14.9)$ & $21(44.7)$ & & \\
\hline \multirow[t]{2}{*}{ Calcified nodule } & No & $45(95.7)$ & 44 (93.6) & 0.000 & 1.000 \\
\hline & Yes & $2(4.3)$ & $3(6.4)$ & & \\
\hline \multirow[t]{3}{*}{ Characteristic of plaque } & Lipid & $31(66.0)$ & $33(70.2)$ & 2.196 & 0.333 \\
\hline & Calcified & $4(8.5)$ & $7(14.9)$ & & \\
\hline & Fibrotic & $12(25.5)$ & $7(14.9)$ & & \\
\hline \multirow[t]{2}{*}{ TCFA } & & $45(95.7)$ & $39(83.0)$ & 2.798 & 0.094 \\
\hline & & $2(4.3)$ & $8(17.0)$ & & \\
\hline $\mathrm{NLA}\left(\mathrm{mm}^{2}\right)$ & & $10.40 \pm 3.38$ & $11.09 \pm 3.20$ & 0.932 & 0.354 \\
\hline Diameter stenosis, \% & & $74.32 \pm 15.81$ & $75.72 \pm 19.51$ & 0.383 & 0.702 \\
\hline Lesion length & & $9.13 \pm 3.48$ & $9.97 \pm 3.94$ & 1.101 & 0.274 \\
\hline \multirow[t]{3}{*}{ Target vessel } & LAD, n (\%) & $35(74.5)$ & $35(74.5)$ & 0.750 & 0.687 \\
\hline & LCX, n (\%) & $5(10.6)$ & $3(6.4)$ & & \\
\hline & RCA, n (\%) & $7(14.9)$ & $9(19.1)$ & & \\
\hline \multirow[t]{3}{*}{ Location of target plaque } & Proximal & $34(72.3)$ & $28(59.6)$ & 2.310 & 0.276 \\
\hline & Mid & $13(27.7)$ & $18(38.3)$ & & \\
\hline & Distal & $0(0.0)$ & $1(2.1)$ & & \\
\hline \multirow[t]{3}{*}{ Number of vascular lesions } & 1 & $20(42.6)$ & $25(53.2)$ & 1.889 & 0.389 \\
\hline & 2 & $17(36.2)$ & $11(23.4)$ & & \\
\hline & 3 & $10(21.3)$ & $11(23.4)$ & & \\
\hline
\end{tabular}

$\overline{F C T}$, fibrous cap thickness; NLA, normal lumen area

difference was observed for other CAG and OCT characteristics. Specifically, the macrophage accumulation in the plaque rupture group was higher than that in the non-plaque rupture with TCFA group ( $P$ $=0.005)$. The incidence rate of thrombus in the plaque rupture group was higher than that in the non-plaque rupture with TCFA group $(P<0.001)$. The NLA of the nonrupture with non-plaque rupture with TCFA group was higher than that of the nonrupture and non-TCFA group $(P=0.003)$. The macrophage accumulation of the TCFA group was higher than that of the nonrupture and non-TCFA group $(P=0.005)$. The incidence rate of thrombus of non-TCFA group was higher than that of the nonrupture and non-TCFA group $(P<0.001)$. The NLA of the nonrupture with non-plaque rupture with TCFA group was higher than that of the nonrupture and non-TCFA group $(P=0.003)$. 
Table 3 Characteristics of coronary risk factors and laboratory data according to OCT indicated plaque vulnerability

\begin{tabular}{|c|c|c|c|c|c|}
\hline & Ruptured plaque & Nonrupture with TCFA & Nonrupture and non-TCFA & $t / Z / x^{2}$ & $P$ \\
\hline Male & $16(94.1)$ & $9(90.0)$ & $46(68.7)$ & 7.174 & 0.028 \\
\hline Age & $58.94 \pm 10.23$ & $50.10 \pm 7.48$ & $55.88 \pm 11.93$ & 1.938 & 0.150 \\
\hline Hypertension & $10(58.8)$ & $3(30.0)$ & $32(47.8)$ & 2.142 & 0.343 \\
\hline Diabetes mellitus & $12(70.6)$ & $7(70.0)$ & $18(26.9)$ & 15.23 & $<0.001$ \\
\hline Current smoking & $10(58.8)$ & $7(70.0)$ & $40(59.7)$ & 0.428 & 0.807 \\
\hline Current drinking & $4(23.5)$ & $2(20.0)$ & $12(17.9)$ & 0.272 & 0.873 \\
\hline Family history of CAD & $2(11.8)$ & $1(10.0)$ & $13(19.4)$ & 1.023 & 0.599 \\
\hline Previous myocardial infarction & $1(5.9)$ & $2(20.0)$ & $12(17.9)$ & 1.926 & 0.382 \\
\hline Previous PCl & $7(41.2)$ & $4(40.0)$ & $10(14.9)$ & 6.898 & 0.032 \\
\hline BMI & $28.38 \pm 3.98$ & $25.94 \pm 1.92$ & $24.23 \pm 3.27$ & 11.03 & $<0.001$ \\
\hline LDL-c (mmol/l) & $2.53 \pm 0.91$ & $2.66 \pm 0.78$ & $2.41 \pm 0.83$ & 0.458 & 0.634 \\
\hline $\mathrm{HDL}-\mathrm{c}(\mathrm{mmol} / \mathrm{l})$ & $0.93 \pm 0.32$ & $0.98 \pm 0.23$ & $0.98 \pm 0.24$ & 0.252 & 0.777 \\
\hline $\operatorname{ApoA1}(g / L)$ & $1.03 \pm 0.28$ & $1.18 \pm 0.34$ & $1.09 \pm 0.25$ & 1.052 & 0.354 \\
\hline ApoB (g/L) & $0.84 \pm 0.26$ & $0.78 \pm 0.18$ & $0.77 \pm 0.19$ & 0.708 & 0.495 \\
\hline TC (mmol/l) & $3.61 \pm 0.98$ & $4.09 \pm 0.79$ & $3.65 \pm 1.04$ & 0.827 & 0.441 \\
\hline TG (mmol/l) & $2.08 \pm 1.02$ & $2.09 \pm 0.91$ & $1.70 \pm 0.90$ & 1.491 & 0.231 \\
\hline Lp(a) (g/L) & $219(147,358)$ & $134(75,302)$ & $191(96,321)$ & 2.141 & 0.343 \\
\hline Uric Acid $(\mu \mathrm{mol} / \mathrm{L})$ & $348.79 \pm 76.98$ & $332.42 \pm 59.12$ & $327.72 \pm 103.26$ & 0.330 & 0.720 \\
\hline eGFR & $112.59 \pm 47.06$ & $105.06 \pm 22.26$ & $106.76 \pm 35.91$ & 0.195 & 0.823 \\
\hline WBC & $7.33 \pm 1.46$ & $7.54 \pm 2.61$ & $7.59 \pm 2.62$ & 0.076 & 0.927 \\
\hline PLT & $223.12 \pm 51.27$ & $256.3 \pm 114.34$ & $230.84 \pm 61.11$ & 0.822 & 0.443 \\
\hline MPV & $11.18 \pm 0.69$ & $11.04 \pm 0.54$ & $10.20 \pm 1.00$ & 10.017 & $<0.001$ \\
\hline$M P V \geq 10.5 \mathrm{fL}$ & $15(88.2)$ & $8(80.0)$ & $24(35.8)$ & 18.929 & $<0.001$ \\
\hline РСТ (\%) & $0.25 \pm 0.06$ & $0.28 \pm 0.11$ & $0.23 \pm 0.06$ & 2.117 & 0.126 \\
\hline PDW & $15.33 \pm 1.2$ & $15.14 \pm 1.71$ & $13.02 \pm 2.35$ & 10.536 & $<0.001$ \\
\hline HCT (\%) & $0.44 \pm 0.05$ & $0.44 \pm 0.03$ & $0.43 \pm 0.04$ & 0.253 & 0.777 \\
\hline $\mathrm{RBC}\left(10 \wedge^{12} / \mathrm{L}\right)$ & $4.77 \pm 0.46$ & $4.86 \pm 0.4$ & $4.77 \pm 0.48$ & 0.166 & 0.848 \\
\hline $\mathrm{HGB}(\mathrm{g} / \mathrm{L})$ & $144.35 \pm 16.82$ & $146.5 \pm 8.77$ & $143.55 \pm 16.21$ & 0.157 & 0.855 \\
\hline EF & $59.51 \pm 10.15$ & $58.13 \pm 12.70$ & $60.69 \pm 7.23$ & 0.432 & 0.651 \\
\hline $\mathrm{HbA1c}$ & $7.47 \pm 1.15$ & $7.05 \pm 1.10$ & $7.20 \pm 1.45$ & 0.363 & 0.696 \\
\hline Clinical Diagnosis & & & & 0.367 & 0.832 \\
\hline UAP & 12 (70.6) & $6(60.0)$ & $43(64.2)$ & & \\
\hline NSTEMI & $5(29.4)$ & $4(40.0)$ & $24(35.8)$ & & \\
\hline Statins & $6(35.3)$ & $4(40.0)$ & $17(25.4)$ & 1.303 & 0.521 \\
\hline Aspirin & $11(64.7)$ & $7(70.0)$ & $51(76.1)$ & 0.937 & 0.626 \\
\hline$\beta$-Blockers & $7(41.2)$ & $2(20.0)$ & $23(34.3)$ & 1.337 & 0.512 \\
\hline ARB/ACEI & $6(35.3)$ & $2(20.0)$ & $28(41.8)$ & 1.965 & 0.374 \\
\hline $\mathrm{CCB}$ & $5(29.4)$ & $2(20.0)$ & $15(22.4)$ & 0.431 & 0.806 \\
\hline
\end{tabular}

Abbreviations are as in Table 1

\section{Discussion}

In this retrospective study we found that the platelet related blood indices MPV and PDW were independently associated with the risk of plaque rupture, while PDW also independently predicted the formation of TCFA in patients with NSTE-ACS. In view of the fact that changes of MPV or PDW reflect changes in platelet functional status, these findings suggest that MPV and PDW may be used as inexpensive markers for risk stratification in NSTE-ACS patients. 
Table 4 Association between patient characteristics and the prevalence of plaque vulnerability: results of multivariate logistic regression analysis

\begin{tabular}{|c|c|c|c|c|c|c|}
\hline \multirow{2}{*}{$\begin{array}{l}\text { Independent } \\
\text { variables }\end{array}$} & \multicolumn{3}{|c|}{ Model 1} & \multicolumn{3}{|c|}{ Model 2} \\
\hline & $P$ & OR & $95 \% \mathrm{Cl}$ & $P$ & OR & $95 \% \mathrm{Cl}$ \\
\hline Diabetes mellitus & 0.043 & 5.242 & $1.056-26.015$ & 0.032 & 6.492 & $1.176-35.849$ \\
\hline BMI & 0.006 & 1.450 & $1.113-1.887$ & 0.358 & 1.135 & $0.867-1.485$ \\
\hline PDW & 0.012 & 1.999 & $1.166-3.425$ & 0.046 & 1.672 & $1.010-2.768$ \\
\hline Gender & 0.095 & 9.288 & $0.681-126.667$ & 0.299 & 3.557 & $0.324-39.002$ \\
\hline Previous PCl & 0.079 & 4.347 & $0.842-22.453$ & 0.172 & 3.232 & $0.601-17.372$ \\
\hline MPV $\geq 10.5 \mathrm{fL}$ & 0.019 & 10.154 & $1.467-70.295$ & 0.069 & 5.611 & $0.873-36.053$ \\
\hline
\end{tabular}

Model 1: plaque rupture; Model 2: TCFA

\section{MPV and coronary plaque vulnerability}

MPV is the most commonly used indicator of platelet size, which may reflect platelet activation [20]. Studies have demonstrated that an increase in MPV may confer similar risks as smoking and obesity for the incidence and prognosis of myocardial infarction and atherosclerosis [21]. Previous studies evaluating the association between MPV and CAD risk focused on clinical outcomes
$[22,23]$. Our study, using OCT, the "gold standard" of current vulnerable plaque judgment in vivo, provided the pathophysiological basis underlying the association between MPV and coronary events by showing that MPV is associated with plaque rupture. Higher MPV has also been associated with CAD risk factors such as hypertension, diabetes, old age, obesity, and smoking $[24,25]$. In our study, higher MPV levels were associated

Table 5 Coronary angiographic characteristics and OCT findings according to OCT features of the plaques

\begin{tabular}{|c|c|c|c|c|c|c|}
\hline & Group & Ruptured plaque & Nonrupture with TCFA & Nonrupture and non-TCFA & $t / Z / x^{2}$ & $P$ \\
\hline \multirow[t]{2}{*}{ Erosion (\%) } & No & $15(88.2)$ & $5(50.0)$ & $55(82.1)$ & 5.465 & 0.065 \\
\hline & Yes & $2(11.8)$ & $5(50.0)$ & $12(17.9)$ & & \\
\hline \multirow[t]{5}{*}{ Macrophage accumulation } & 0 & $3(17.6)$ & $2(20.0)$ & $37(55.2)$ & 19.328 & 0.005 \\
\hline & 1 & $7(41.2)$ & $3(30.0)$ & $18(26.9)$ & & \\
\hline & 2 & $6(35.3)$ & $4(40.0)$ & $12(17.9)$ & & \\
\hline & 3 & $0(0.0)$ & $1(10.0)$ & $0(0.0)$ & & \\
\hline & 4 & $1(5.9)$ & $0(0.0)$ & $1(1.5)$ & & \\
\hline \multirow[t]{2}{*}{ Vasa vasorum } & No & $16(94.1)$ & $8(80.0)$ & $63(94.0)$ & 2.596 & 0.261 \\
\hline & Yes & $1(5.9)$ & $2(20.0)$ & $4(6.0)$ & & \\
\hline \multirow[t]{2}{*}{ Thrombus } & No & $4(23.5)$ & $4(40.0)$ & $58(86.6)$ & 29.624 & $<0.001$ \\
\hline & Yes & $13(76.5)$ & $6(60.0)$ & $9(13.4)$ & & \\
\hline $\mathrm{NLA}\left(\mathrm{mm}^{2}\right)$ & & $13.52 \pm 3.18$ & $10.46 \pm 2.59$ & $10.16 \pm 3.14$ & 6.332 & 0.003 \\
\hline Rate of stenosis & & $81.12 \pm 15.89$ & $72.50 \pm 16.54$ & $73.85 \pm 18.16$ & 1.267 & 0.287 \\
\hline Lesion length & & $10.21 \pm 4.65$ & $9.40 \pm 3.37$ & $9.40 \pm 3.55$ & 0.325 & 0.723 \\
\hline \multirow[t]{2}{*}{ Calcified nodule } & No & $17(100.0)$ & $10(100.0)$ & $62(92.5)$ & 0.979 & 0.763 \\
\hline & Yes & $0(0.0)$ & $0(0.0)$ & $5(7.5)$ & & \\
\hline \multirow[t]{3}{*}{ Target vessel } & LAD & $10(58.8)$ & $8(80.0)$ & $52(77.6)$ & 3.396 & 0.458 \\
\hline & LCX & $2(11.8)$ & $1(10.0)$ & $5(7.5)$ & & \\
\hline & RCA & $5(29.4)$ & $1(10.0)$ & $10(14.9)$ & & \\
\hline \multirow[t]{3}{*}{ Location of target plaque } & Pro & $10(58.8)$ & $7(70.0)$ & $45(67.2)$ & 4.296 & 0.439 \\
\hline & Mid & $6(35.3)$ & $3(30.0)$ & $22(32.8)$ & & \\
\hline & Distal & $1(5.9)$ & $0(0.0)$ & $0(0.0)$ & & \\
\hline \multirow[t]{3}{*}{ Number of vascular lesions } & 1 & $9(52.9)$ & $5(50.0)$ & $31(46.3)$ & 0.411 & 0.982 \\
\hline & 2 & $5(29.4)$ & $3(30.0)$ & $20(29.9)$ & & \\
\hline & 3 & $3(17.6)$ & $2(20.0)$ & $16(23.9)$ & & \\
\hline
\end{tabular}


with obesity and dyslipidemia, which is consistent with previous findings. However, after adjusting for confounding factors, we found that MPV independently predicted plaque rupture as evidenced by multivariate logistic regression analyses. These findings indicate that an incremental increase in MPV reflects platelet activation. Indeed, many recent studies have linked platelet activity to the development and progression of atherosclerosis [26], especially in patients with ACS. MPV has been found to be higher in ACS patients compared to those with stable CAD [27]. Our data also confirmed $\mathrm{MPV}$ as an independent predictor of 6-month mortality or nonfatal myocardial infarction in ACS patients [28]. Incorporating MPV in GRACE's risk score has been suggested to improve the validity of risk stratification in ACS. Patients with high MPV and high troponin levels had a 4.8-fold increased risk of coronary artery disease [29]. However, a previous study suggested that lower MPV levels were associated with the incidence of MACE in patients with stable angina [30]. Taken together, the relationship between changes in platelet volume and the progression of coronary heart disease may be inconsistent in different subtypes of CAD, which should be confirmed in future studies with larger sample sizes.

Our results are consistent with previous experimental findings that demonstrated that large platelets may be more likely activated, leading to platelet adhesion and aggregation, resulting in a pro-atherosclerotic effect [30, 31]. Large platelets are rich in secretory granules and have a stronger metabolism and enzyme activity. Furthermore, increases in platelet volume lead to the release of young platelets in the bone marrow, which are more reactive and exhibit an enhanced pro-thrombotic activity [32]. In contrast, increased inflammatory factors during acute coronary events may further change platelet morphology and reactivity [33], leading to higher MPV levels. The result is a vicious cycle that exacerbates the course of the disease. However, more experiments are needed to explore the molecular mechanism for changes in MPV in patients with NSTE-ACS.

\section{PDW and coronary plaque vulnerability}

PDW refers to the degree of difference in platelet volume, expressed as the degree of variation in single platelet volume. Increased PDW indicates that platelet volume is not uniform and individual volumes vary greatly. When platelets are activated, they undergo morphological changes by forming pseudopodia, leading to changes in PDW. As a result, platelets become larger and reactive, thus increasing PDW. Furthermore, PDW has also been regarded as a more concrete parameter for platelet activation than MPV, as it does not increase during simple platelet swelling $[34,35]$. Accordingly, some studies have suggested a potential relationship between
PDW and CAD [36, 37]. Our study showed that PDW was an independent risk factor for plaque rupture as well as TCFA occurrence in NSTE-ACS patients. These results may reflect rapid platelet consumption and activation in patients with unstable coronary plaques. Although the accurate mechanism is unclear, our findings support that PDW confers more predicted efficacy to plaque vulnerability in NSTE-ACS patients since it was associated with plaque rupture and the formation of TCFA under OCT. Further studies are needed to confirm our findings and expand the role of PDW in risk stratification in NSTE-ACS patients.

\section{Study limitations}

There are several limitations in this study that should be acknowledged. First, this study is a retrospective observational single-center study, and results of our study should be confirmed with prospective cohort studies. Secondly, we focused on coronary plaques in culprit vessels. Predictors for the plaque composition of non-target lesions were not analyzed. Thirdly, large residual thrombi may blur the lumen boundary and the underlying plaques, making it difficult to assess the underlying plaque characteristics. Finally, this study attached undue importance to qualitative differences of coronary plaques and thus ignored the observation of spatial distribution of different plaques.

\section{Conclusions}

Higher MPV and PDW are independently associated with higher risk of plaque vulnerability, as evidenced by OCT analysis in our cohort of NSTE-ACS patients. Potential uses of MPV and PDW for risk stratification in NSTE-ACS patients deserve further investigation.

\section{Abbreviations \\ ACEl: Angiotensin-converting enzyme inhibitors; ACS: Acute coronary syndrome; apo-Al: Apolipoprotein A1; apo-B: Apolipoprotein B; \\ ARB: Angiotensin receptor blocker; BPC: Blood platelet count; CAG: Coronary angiography; CCB: Calcium channel blockers; Cr: Creatinine; DBil: Direct bilirubin; FCT: Fibrous cap thickness; HCT: Hematocrit; HDL-c: High-density lipoprotein cholesterol; HGB: Hemoglobin; LDL-c: Low-density lipoprotein- cholesterol; Lp(a): Lipoprotein (a); MPV: Mean platelet volume; NLA: Normal lumen area; NSTE-ACS: Non-ST-elevation ACS; OCT: Optical coherence tomography; PCI: Percutaneous coronary intervention; PCT: Thrombocytocrit; PDW: Platelet distribution width; PLT: Blood platelet; RBC: Red blood cell; SMC: Smooth muscle cell; TBil: Total bilirubin; TC: Total cholesterol; TCFA: Thin-cap fibroatheroma; TG: Triglyceride}

\section{Acknowledgments}

Not Applicable.

\section{Authors' contributions}

Conceived and designed the study: YY and JP. Data collection and analyzed the data: XL. Quality control the study and revision: FL,XL,SJ and LJ. Wrote the paper: JW. The manuscript was approved by all above authors.

\section{Funding}

This work was supported by a project grant from Science and Technology Program of Xinjiang Uyghur Autonomous Region, China (No.2016E02072) 
and project grants of the Research on Prevention and Control of Major Chronic Noncommunicable Diseases of China (No.2018YFC1312804). This study was supported by research grants from the First Affiliated Hospital of Xinjiang Medical University to Dr. Yang Yining. The funders had no role in study design, data collection and analysis,

decision to publish, or preparation of the manuscript

\section{Availability of data and materials}

The data that support the findings of this study are available from the First Affiliated Hospital of Xinjiang Medical University but restrictions apply to the availability of these data, which were used under license for the current study, and so are not publicly available. Data are however available from the authors upon reasonable request and with permission of the First Affiliated Hospital of Xinjiang Medical University.

\section{Ethics approval and consent to participate}

The study protocol was approved by the ethics committee of the First affiliated hospital of Xinjiang Medical University. Because of the retrospective design of the study, the need to obtain informed consent from eligible patients was waived by the ethics committee.

\section{Consent for publication}

Not applicable.

\section{Competing interests}

The authors declare that they have no competing interest.

\section{Author details}

${ }^{1}$ Department of Coronary Heart Disease, the First Affiliated Hospital of Xinjiang Medical University, Urumqi 830011, China. ${ }^{2}$ The Renji Hospital of Shanghai Jiao Tong University, Shanghai 200240, China.

\section{Received: 2 January 2019 Accepted: 21 May 2019}

Published online: 29 May 2019

\section{References}

1. Lozano R, Naghavi MK, Foreman K, et al. Global and regional mortality from 235 causes of death for 20 age groups in 1990 and 2010:a systematic analysis for the global burden of disease study 2010[J]. Lancet. 2012; 380(9859):2095-128.

2. Altan $\mathrm{O}$, Ibrahim $\mathrm{S}$, Gülay $\mathrm{H}$, et al. Predictors of abdominal obesity and high susceptibility of cardiometabolic risk to its increments among Turkish women: a prospective population-based study.[J]. Metab Clin Exp. 2007;56: 348-56.

3. Khot UN, Khot MB, Bajzer CT, et al. Prevalence of conventional risk factors in patients with coronary heart disease. JAMA. 2003;290:898-904.

4. Greenland P, Knoll MD, Stamler J, Neaton JD, Dyer AR, Garside DB, Wilson PW. Major risk factors as antecedents of fatal and nonfatal coronary heart disease events. JAMA. 2003;290:891-7.

5. Kaplan ZS, Jackson SP. The role of platelets in atherothrombosis.[J]. Hematology Am Soc Hematol Educ Program. 2011;2011(1):51-61.

6. Lippi G, Salvagno GL, Nouvenne A, et al. The mean platelet volume is significantly associated with higher glycated hemoglobin in a large population of unselected outpatients [J]. Prim Care Diabetes. 2015;9(4):226-30.

7. Yuri GA, Lilit A, Mikhailidis Dimitri $P$, et al. Mean platelet volume: a link between thrombosis and inflammation?[J]. Curr Pharm Des. 2011;17:47-58.

8. Nardin Matteo,Verdoia Monica,Barbieri Lucia et al. Impact of metabolic syndrome on mean platelet volume and its relationship with coronary artery disease.[J]. Platelets, 2018, undefined: 1-9.

9. Sansanayudh N, Anothaisintawee T, Muntham D, et al. Mean platelet volume and coronary artery disease: a systematic review and meta-analysis. [J]. Int J Cardiol. 2014;175(3):433-40.

10. Dogan A, Aksoy F, Icli A, et al. Mean platelet volume is associated with culprit lesion severity and cardiac events in acute coronary syndromes without ST elevation. Blood Coagul Fibrinolysis. 2012;23:324-30.

11. Varol E, Uysal BA, Dogan A, et al. Mean platelet volume has a prognostic value in patients with coronary artery ectasia. Clin Appl Thromb Hemost. 2012;18:387-92.

12. Mendis S, Thygesen K, Koulasmaa K et a1. Wodd Health Organization definition of myocardial infarction:2008-09 revision [J]. Int J Epidemiol, 2011, 40(1):139.146.DOl:https://doi.org/10.1093/ije/dyq165.
13. Wang J, Zhang L, Wang F, Liu L, Wang H. China National Survey of chronic kidney disease working group. Prevalence, awareness, treatment, and control of hypertension in China: results from a national survey. Am J Hypertens. 2014;27(11):1355-61.

14. Olafsdottir E, Andersson DK, Dedorsson I, Stefánsson E. The prevalence of retinopathy in subjects with and without type 2 diabetes mellitus. Acta Ophthalmol. 2014;92(2):133-7.

15. Joint Committee for the Revision of Guidelines for Prevention and Treatment of Dyslipidemia in Chinese Adults. Guidelines for the Prevention and Treatment of Dyslipids in Chinese Adults (Revised 2016). Zhongguo Xun Huan Za Zhi, 2016, 31(10):937-950.

16. MIAO L-z, Yao LU, Chen-Xu QU, et al. Monitoring of antiplatelet therapy and changes of mean platelet volume after percutaneous coronary intervention in the patients with coronary heart disease. Chin J Clin Lab Sci. 2017;35(6):439-43.

17. Wei $G$, Wang $X$, Jingyao $F$, et al. Impact of Obstructive Sleep Apnea on Platelet Function Profiles in Patients With Acute Coronary Syndrome Taking Dual Antiplatelet Therapy.[J]. J Am Heart Assoc. 2018;7:e008808.

18. Jia H, Abtahian F, Aguirre AD, Lee S, Chia S, Lowe H, Kato K, Yonetsu T, Vergallo R, Hu S, Tian J, Lee H, Park SJ, Jang YS, Raffel OC, Mizuno K, Uemura S, Itoh T, Kakuta T, Choi SY, Dauerman HL, Prasad A, Toma C, McNulty I, Zhang S, Yu B, Fuster V, Narula J, Virmani R, Jang IK. In vivo diagnosis of plaque erosion and calcified nodule in patients with acute coronary syndrome by intravascular optical coherence tomography. J Am Coll Cardiol. 2013;62:1748-58.

19. Jiannan D, Lei $X$, Haibo J, et al. In vivo predictors of plaque erosion in patients with ST-segment elevation myocardial infarction: a clinical, angiographical, and intravascular optical coherence tomography study.[J]. Eur Heart J. 2018:39:2077-85.

20. Ki YJ, Park S, Ha SI, et al. Usefulness of mean platelet volume as a biomarker for long-term clinical outcomes after percutaneous coronary intervention in Korean cohort:a comparable and additive predictive value to high-sensitivity cardiac troponin T and N-terminal pro-B type natriur [J]. Platelets. 2014;25(6):427.

21. Slavka G, Perkmann T, Haslacher $H$, et al. Mean platelet volume may represent a predictive parameter for overall vascular mortality and ischemic heart disease. Arterioscler Thromb Vasc Biol. 2011;31:1215-8.

22. Murat SN, Duran M, Kalay N, et al. Relation between mean platelet volume and severity of atherosclerosis in patients with acute coronary syndromes [J]. Angiology. 2013;64(2):131-6.

23. Sansanayudh $N$, Numthavaj $P$, Muntham $D$, et al. Prognostic effect of mean platelet volume in patients with coronary artery disease. A systematic review and meta-analysis.[J]. Thromb. Haemost. 2015;114:1299-309.

24. De Luca G, Secco GG, Verdoia M, et al. Combination between mean platelet volume and platelet distribution width to predict the prevalence and extent of coronary artery disease:results from a large cohort study [J]. Blood Coagul Fibrinolysis. 2014;25(1):86-91.

25. Cho SY, You E, Lee HJ, et al. Smoking cession decreases mean platelet volume in healthy Korean populations [J]. Clin Lab. 2014;60(8):1413-6.

26. Borissoff Jl, Spronk HM, ten Cate H. The hemostatic system as a modulator of atherosclerosis. N Engl J Med. 2011;364:1746-60.

27. Wen-liang XU, Yue WU, Bo HUI, et al. The Changes of Mean Platelet Volume and its Related Factors in Patients With Coronary Artery Disease [J]. Chin Circul J. 2012;27(4):262-5.

28. Xiaowei N, Yang C, Yiming Z, et al. Mean platelet volume on admission improves risk prediction in patients with acute coronary syndromes.[J]. Angiology. 2015;66(5):456-63.

29. Tuncay T, Harsimran S, Igor W, et al. Usefulness of Mean Platelet Volume to Predict Significant Coronary Artery Disease in Patients With Non-STElevation Acute Coronary Syndromes.[J]. Am J Cardiol. 2017;119(2):192-6.

30. Hideki W, Tomotaka D, Katsumi M, et al. Mean platelet volume and longterm cardiovascular outcomes in patients with stable coronary artery disease.[J]. Atherosclerosis. 2018;277:108-12

31. Kamińska J, Koper Olga M, Siedlecka-Czykier E, et al. The utility of inflammation and platelet biomarkers in patients with acute coronary syndromes.[J]. Saudi J Biol Sci. 2018;25:1263-71.

32. Pereg D, Berlin T, Mosseri M. Mean platelet volume on admission correlates with impaired response to thrombolysis in patients with ST-elevation myocardial infarction. Platelets. 2010;21(2):117-21.

33. Ulutas KT, Dokuyucu R, Sefil F, et al. Evaluation of mean platelet volume in patients with type 2 diabetes mellitus and blood glucose regulation:a marker for atherosclerosis? [J]. Int J Clin Exp Med. 2014;7(4):955-61. 
34. Varasteh-ravan HR, Ali-Hassan-Syegh S, Shokraneh S, et al. Relationship of admission mean platelet volume, platelet distribution width and white blood cells with ST resolution inpatients with acute ST segment elevation myocardial infarction treated with streptokinase without history of previous cardiovascular surgery. Perspect Clin Res. 2013;4(2):125-9.

35. El-Dosouky II, Shehata IE. Value of the mean platelet volume in evaluation of patients with acute coronary syndrome. J Med Diagn Methods. 2016;5(1):1-5.

36. Cetin M, Bakirci EF, Baysal E, et al. Increased platelet distribution width is associated with ST-segment elevation myocardial infarction and thrombolysis failure. Angiology. 2014;65(8):737-43.

37. Başak $T$, Zuhal YA, Fatih A, et al. Platelet indices (mean platelet volume and platelet distribution width) have correlations with periodontal inflamed surface area in coronary artery disease patients: A pilot study.[J]. J. Periodontol. 2018;89:1203-12.

\section{Publisher's Note}

Springer Nature remains neutral with regard to jurisdictional claims in published maps and institutional affiliations.

Ready to submit your research? Choose BMC and benefit from:

- fast, convenient online submission

- thorough peer review by experienced researchers in your field

- rapid publication on acceptance

- support for research data, including large and complex data types

- gold Open Access which fosters wider collaboration and increased citations

- maximum visibility for your research: over $100 \mathrm{M}$ website views per year

At $\mathrm{BMC}$, research is always in progress.

Learn more biomedcentral.com/submissions 